\title{
Microbiological Characteristics of Trachanas, a Traditional Fermented Dairy Product from Cyprus
}

\author{
Despina Bozoudi, Maria Agathokleous, Iacovos Anastasiou, \\ Photis Papademas, and Dimitris Tsaltas \\ Department of Agricultural Sciences, Biotechnology and Food Science, Cyprus University of Technology, 3036 Limassol, Cyprus \\ Correspondence should be addressed to Dimitris Tsaltas; dimitris.tsaltas@cut.ac.cy
}

Received 15 May 2017; Revised 3 September 2017; Accepted 19 September 2017; Published 17 October 2017

Academic Editor: Effie Tsakalidou

Copyright (c) 2017 Despina Bozoudi et al. This is an open access article distributed under the Creative Commons Attribution License, which permits unrestricted use, distribution, and reproduction in any medium, provided the original work is properly cited.

\begin{abstract}
The purpose of this study was to characterize the autochthonous microbiota of Cypriot Trachanas, a traditional fermented ewes' milk product. For this reason, 12 samples of raw and fermented milk as well as natural starter culture were collected in order to count, isolate, and identify the main species present during Trachanas fermentation. In total, 198 colonies were retrieved and 163 were identified by sequencing analysis at species level. Lactic acid bacteria (LAB) were the predominant group, followed by yeasts. Lactococcus, Lactobacillus, and Enterococcus were frequently isolated from raw milk, and Lactobacillus casei/paracasei predominated in the starter culture. Lactococcus lactis was isolated in high frequency (27.9\% of the isolates) at the beginning, while Lactobacillus spp. (20\%) and Saccharomyces unisporus (17.9\%) were isolated at the end of fermentation. After assessing their technological potential, selected strains could be used as starters to ferment milk for artisanal Trachanas production.
\end{abstract}

\section{Introduction}

Trachanas is a dry mixture of fermented milk and crushed grain of wheat. Trachanas and Trachanas-like products are also known under different names in many countries such as tarhana in Turkey, kishk in Egypt, Jordan, Lebanon, Palestine, and Syria, kushuk in Iraq, tarkhineh in Iran, talkuna in Finland, and thanu in Hungary [1-4].

Trachanas is also produced in Cyprus and is the most known and characteristic traditional product of the country, while also being a very common meal (consumed at least once a week in most households and exported for specialty artisanal product stores). The product may be produced throughout the country with the most renowned being the one at Statos-Agios Fotios in Paphos district, favoured by the dry and warm days followed by cool nights considered as excellent drying conditions. Trachanas is mainly produced during the summertime, when milk quantities are large and weather is conducive for proper fast drying. It is a sun-dried product, although newer facilities have introduced air-flow oven drying in order to maximize productivity and meet the needs during winter, as well. Trachanas and all similar products have high nutritive value, low $\mathrm{pH}$, and sour taste. Lactic acid bacteria (LAB) and yeasts are responsible for milk acidification, as well as the formation of several volatile odour compounds [5-7].

Trachanas is consumed mostly in winter as a soup after reconstitution of dried pieces in hot water and boiling. Its chemical composition and nutritive value depend highly on the type of milk used and to a lesser extent on the wheat. Its nutritional value though depends also on the metabolic products derived from a mixed population of lactic acid bacteria and yeasts [2]. The amount of the two main ingredients also affects these parameters, although usual proportion is $2: 1$ (milk: wheat). The milk is primarily of sheep, although goat and mixture of them are also common. Contrary to similar products, the fermentation is initiated by autochthonous milk microbiota, although traditional yogurt is used in warmer areas as a starter to avoid technological and safety problems. Broken wheat is then added to the fermented milk and heated to cook the mixture and then a thick paste is left to cool and cut into pieces (usually $10 \mathrm{~cm} \times 3-4 \mathrm{~cm}$ ) and left to dry (sun or oven drying). 
Commercial starter cultures are not normally used in making artisanal dairy products. LAB naturally present in the milk and usually serve as starters to milk fermentation. On the other hand, natural cultures produced by incubating milk from the previous day under defined conditions are used for this purpose and are known as artisanal cultures [8]. It is well known that the typicality of traditional dairy products is linked mainly to the microbes originating from the milk [9]. The biodiversity of these microorganisms could therefore be considered as a fundamental factor for the features and quality of these artisanal products [10].

Raw milk's microbiota is known to be an expression of the local ecosystem and it can have an impact on the characteristics of the final product [11]. Since the typicity is linked to the "terroir," it realizes and expresses the effect of the "terroir" on a product, distinguishing the product linked with this territory from similar ones produced elsewhere. In the case of sheep and goats in particular, the milk is usually processed on the farm itself, without any treatment to control the native microbiota.

Traditional Cypriot Trachanas is produced with raw sheep milk or mixture of sheep and goat locally produced milk, which means that the product is closely linked to the ecosystem of the production zone. The diversity in the microbial flora of raw milk contributes to the peculiar sensory features among this kind of traditional products. Indeed, many of the characteristics desired by consumers are not present or are far less evident in products from pasteurized milk [12].

Quality and reproducibility of fermented milks and processes are ensured by using industrial starters. Nevertheless, consumers prefer traditional fermented milks, since artisanal starters give these products a complexity in flavour [13]. This led some authors to isolate and characterise artisanal strains in order to provide sensorial properties similar to those of traditional products [14-16].

Up to now, the microbiota involved in traditional Cypriot Trachanas is unknown. This is the first attempt to study the milk's microbial community participating in the fermentation of Cypriot Trachanas. The main objectives were to count, isolate, and identify those microorganisms that are related to milk fermentation for Trachanas production in order to be further studied and selected as starter cultures. Changes in microbiological counts and composition of milk used for Trachanas during fermentation were studied. The progress of fermentation for both inoculum and fermented milk will be presented.

\section{Materials and Methods}

2.1. Sample Collection. The sampling took place at a small, family-owned facility, at Statos-Agios Fotios, in Paphos district, where Trachanas has been traditionally produced for centuries. Twenty litres of inoculum (starter culture), prepared from naturally fermented ewes' milk (with up to $\sim 10 \%$ of goat milk), was used to initiate the fermentation of $380 \mathrm{~L}$ of raw milk in an open-type vat. No temperature control is applied at any stage and fermentation takes place at room temperature that fluctuates between $20^{\circ} \mathrm{C}$ and $30^{\circ} \mathrm{C}$ (night and day). Samples of raw and fermented milk, as well as the inoculum, were collected at four consecutive weeks at midsummer. One litre of milk was collected for a time period of 5 days before the addition of broken wheat and the boiling of Trachanas. Finally, the Trachanas was sundried until constant weight. The milk samples were kept into isothermal containers at $4^{\circ} \mathrm{C}$, brought to the laboratory, and plated in duplicate at the same day.

2.2. Microbiological Analysis. The samples were evaluated for total aerobic bacteria on Plate Count Milk Agar $\left(30^{\circ} \mathrm{C}\right.$ for $72 \mathrm{~h}$ ) and LAB on MRS agar, pH 6.2 [17], as well as MRS agar acidified at $\mathrm{pH} 5.7$ with $1 \mathrm{~N} \mathrm{HCl}\left(30^{\circ} \mathrm{C}\right.$ for 5 days $)$ and $\mathrm{LAB}$ on $\mathrm{M} 17$ agar containing $5 \mathrm{~g} / \mathrm{L}$ lactose $\left(30^{\circ} \mathrm{C}\right.$ for $\left.48 \mathrm{~h}\right)$ and finally yeasts and moulds in Yeast Malt Chloramphenicol Agar $\left(25^{\circ} \mathrm{C}\right.$ for 5 days) by the standard plate method after serial dilutions in sterile MRD (Maximum Recovery Diluent). Cycloheximide (Sigma, USA) was added $(100 \mathrm{mg} / \mathrm{mL})$ to prevent the growth of yeasts in MRS agar, $\mathrm{pH}$ 6.2, MRS agar, $\mathrm{pH}$ 5.7, and M17 agar [18]. The colonies between 30 and 300 on each Petri dish were counted. Randomly selected isolates from raw milk, fermented milk during 5 days, and the milk used as starter, from all media used, were isolated according to different morphological characteristics (i.e., size, shape, and/or color). Purity of the isolates was checked by streaking on the respective media, followed by microscopic examination. Stock cultures of the isolates were stored in MRS, M17, and/or YM broth plus glycerol (75:25) as cryoprotective agent at $-80^{\circ} \mathrm{C}$. Totally, 163 isolates were retrieved. Gram staining and catalase test were performed in all bacterial isolates. All media were obtained from Oxoid (Hampshire, England), unless otherwise stated.

2.3. Identification of the Isolates by Sequence Analysis. Overnight, $2 \mathrm{~mL}$ liquid cultures in MRS, M17, and Yeast Malt Chloramphenicol Agar and/or Nutrient Broth were grown in order to collect viable cells. DNA extraction was performed using a commercial kit (Invitrogen, Carlsbad, CA, USA) and following the manufacturers' instructions. The 16S rRNA gene fragments of $\sim 900 \mathrm{bp}$ of the bacterial DNA were amplified with the primers 27F ( $5^{\prime}$-AGAGTTTGATCCTGGCTCAG- $\left.3^{\prime}\right)$ and 926R ( $5^{\prime}$-CCGTCAATTCMTTTRAGTTT- $\left.3^{\prime}\right)$ according to Luo et al. [19]. Yeast DNA was amplified with the set of primers ITS1-F ( $5^{\prime}$-TCCGTAGGTGAACCTGCGG-3') and ITS4-R ( $5^{\prime}$-TCCTCCGCTTATTGATATGC- $\left.3^{\prime}\right)$ according to Tristezza et al. [20] using a thermal cycler (C1000, Bio-Rad, USA). Amplification products were separated by electrophoresis on $1 \%(\mathrm{w} / \mathrm{v})$ agarose gel in $1 \mathrm{x}$ TAE buffer, stained with SYBR Safe DNA gel stain (Invitrogen, USA), and visualized under UV light.

PCR products were purified with a PCR Clean-Up System kit (Macherey-Nagel, Düren, Germany) and sequenced (3130 Genetic Analyzer, Applied Biosystems) with the same pair of primers used for amplification. Homology searches of the $16 \mathrm{~S}$ rRNA gene sequences and ITS1-ITS4 region sequences were performed in the GenBank database using the BLAST algorithm (http://www.ncbi.nlm.nih.gov/BLAST/). Identification of the isolates was determined on the basis of the highest matching score. 
TABLE 1: Populations $\left(\log _{10} \mathrm{cfu} / \mathrm{ml}\right)^{1}$ and $\mathrm{pH}$ values of raw and fermented milk, as well as traditional starter used for Trachanas production.

\begin{tabular}{|c|c|c|c|c|c|c|c|}
\hline & \multirow{2}{*}{ Raw milk } & \multirow{2}{*}{ Starter } & \multicolumn{5}{|c|}{ Fermented milk } \\
\hline & & & Day 1 & Day 2 & Day 3 & Day 4 & Day 5 \\
\hline LAB on MRS agar, $\mathrm{pH} 6.2$ & $3.79 \pm 0.50$ & $7.56 \pm 0.40$ & $5.20^{\mathrm{a}} \pm 0.20$ & $7.30^{\mathrm{bc}} \pm 0.98$ & $7.71^{c} \pm 1.10$ & $7.92^{\mathrm{c}} \pm 0.41$ & $6.89^{b} \pm 0.61$ \\
\hline LAB on MRS agar, pH 5.7 & $2.99 \pm 0.54$ & $7.52 \pm 0.30$ & $5.13^{\mathrm{a}} \pm 0.16$ & $6.83^{\mathrm{b}} \pm 0.83$ & $7.76^{\mathrm{C}} \pm 0.43$ & $7.36^{b c} \pm 0.51$ & $6.97^{\mathrm{b}} \pm 0.40$ \\
\hline LAB on M17 agar & $3.84 \pm 0.43$ & $5.48 \pm 0.73$ & $3.82^{\mathrm{a}} \pm 0.49$ & $5.18^{\mathrm{b}} \pm 0.44$ & $5.48^{\mathrm{b}} \pm 0.22$ & $5.62^{\mathrm{b}} \pm 0.71$ & $5.49^{\mathrm{b}} \pm 0.27$ \\
\hline Yeasts & $2.78 \pm 0.63$ & $5.23 \pm 0.68$ & $3.23^{\mathrm{a}} \pm 0.69$ & $3.93^{\mathrm{ab}} \pm 0.54$ & $4.98^{\mathrm{bc}} \pm 0.92$ & $5.53^{\mathrm{c}} \pm 0.81$ & $5.54^{\mathrm{c}} \pm 0.67$ \\
\hline Total aerobic counts & $4.66 \pm 0.38$ & $8.26 \pm 0.08$ & $5.89^{\mathrm{a}} \pm 0.24$ & $7.59^{b c} \pm 1.06$ & $8.41^{\mathrm{d}} \pm 0.11$ & $8.14^{\mathrm{C}} \pm 0.19$ & $7.23^{\mathrm{b}} \pm 1.13$ \\
\hline $\mathrm{pH}$ & $6.8 \pm 0.05$ & $3.8 \pm 0.02$ & $6.7^{\mathrm{a}} \pm 0.05$ & $6.6^{\mathrm{a}} \pm 0.05$ & $4.3^{\mathrm{b}} \pm 0.02$ & $4.2^{\mathrm{b}} \pm 0.03$ & $3.8^{\mathrm{C}} \pm 0.01$ \\
\hline
\end{tabular}

${ }^{1}$ Mean values of four samples counted in duplicate $(x \pm \mathrm{SD} ; n=8) .{ }^{\mathrm{a}, \mathrm{b}, \mathrm{c}, \mathrm{d}}$ Comparison between days of fermentation. For each row, means followed by different superscript lowercase letters are significantly different, at significance level of $P<0.05$, according to the LSD criterion.

2.4. $p H$ Determination of the Samples. In order to monitor the fermentation process, the $\mathrm{pH}$ of the milk samples was determined. $100 \mathrm{~mL}$ of raw and fermented milk, as well as the inoculum, was used to measure the $\mathrm{pH}$ (glass electrode, Hanna Instruments, Padova, Italy). The assay was performed in triplicate.

2.5. Statistical Analysis. Data for microbiological counting from fermented milk samples were summarized by calculating indices of central tendency (mean values) and indices of dispersion (standard deviations). The Least Significance Difference (LSD) criterion was used for testing differences among means. The corresponding standard error of mean differences was estimated through the implementation of appropriate one-way ANOVA model after a log transformation of bacterial count numbers. Statistical analysis was performed with the SPSS v.15 software (SPSS Inc., Chicago, IL, USA). In all hypothesis testing procedures, the significance level was predetermined at $P<0.05$.

\section{Results and Discussion}

3.1. Microbiological Evaluation of the Samples. The results on microbial counts in raw milk and traditional starter samples are presented in Table 1. Lactic acid bacteria (LAB) counted in M17 agar, MRS agar, pH 6.2, and MRS agar, pH 5.7, constituted the predominant microbiota of the raw milk samples, and their numbers ranged from 2.99 to $3.79 \log _{10} \mathrm{cfu} / \mathrm{ml}$, lower than those found by Gaya et al. [21], in raw milk used for Spanish Manchego cheese. The mean number of yeasts found in raw milk samples was $2.78 \log _{10} \mathrm{cfu} / \mathrm{ml}$, which is comparable to the mean yeast count in raw milk from farms located in different areas of Sardinia [22] and Normandy [23]. It is documented that yeasts occur in raw milk at insignificant numbers [24] probably due to competitive utilization for the growth substrates by psychrotrophic bacteria of milk or owing to inhibition by metabolites excreted by bacteria [25].

The log counts of LAB on MRS agar, $\mathrm{pH} 6.2$ and $\mathrm{pH}$ 5.7, of the artisanal culture studied were found at high levels (7.56 and $7.52 \log _{10} \mathrm{cfu} / \mathrm{ml}$, resp.; Table 1), as expected, while LAB at M17 agar and yeasts were counted at levels: 5.48 and $5.23 \log _{10} \mathrm{cfu} / \mathrm{ml}$, respectively. This artisanal starter culture is composed of fermented milk taken from the previously produced batch when the $\mathrm{pH}$ decreases to 3.8 in order to inoculate the new batch. Thus, this natural starter is continuously evolving as an undefined mixture composed of several strains and/or species of LAB.

During the fermentation period, LAB on MRS agar, $\mathrm{pH}$ 6.2, and LAB on M17 agar reached their higher numbers at day 4 and total aerobic counts and LAB on MRS agar, $\mathrm{pH}$ 5.7, at day 3. A significant $(P<0.05)$ decrease in their population was noticed at the end of the fermentation, probably due to the acidic conditions created by the drastic reduction of $\mathrm{pH}$ caused by NSLAB (3.8 pH units; Table 1). Sengun et al. [26] report that LAB counts and acidity of Turkish tarhana depend on the availability of fermentative substrates and the fermentation time and temperature used in the production. On the other hand, yeasts kept their high levels $(P<0.05)$ until the end of fermentation process, as also noticed for LAB on M17 agar. Despite the increase in yeast numbers, the population of NSLAB remains constant or continues to increase probably due to a symbiotic effect, whereby both populations benefit from the interaction. This mutualistic effect may be attributed to the yeasts providing the necessary growth factors and vice versa [25]. Lazos et al. [27], studying the fermentation process of Greek trahanas, found high numbers of yeasts $\left(\sim 6 \log _{10} \mathrm{cfu} / \mathrm{ml}\right)$ after $35 \mathrm{~h}$ of fermentation, while LAB and total aerobic counts were traced at even higher numbers $\left(\sim 10 \log _{10} \mathrm{cfu} / \mathrm{ml}\right)$. On the other hand, Daglioglu et al. [28] noticed that total mesophilic aerobic bacteria, yeasts, and LAB counts of Turkish tarhana reached maximum levels at the second day and decreased to their initial levels at the end of fermentation.

3.2. Identification of the Predominant Microbiota. In total, 163 bacteria and yeasts colonies were isolated from raw and fermented milk samples, as well as the artisanal starter culture, and submitted to molecular identification (Table 2). $\mathrm{LAB}$ were the predominant group of microorganisms (122 strains; $72.6 \%$ of the isolates), followed by yeasts (38 strains; $22.7 \%)$. Some other species were sporadically found, such as Staphylococcus spp. (3 strains; $1.8 \%$ of the isolates), Macrococcus caseolyticus (2 strains; 1.2\%), Enterobacter spp. (1 strain; 0.6\%), Acinetobacter spp. (1 strain; 0.6\%), and Acetobacter cibinongensis (1 strain; $0.6 \%$ of the isolates). The strains under consideration shared $96-100 \%$ similarity with the respective species. 
TABLE 2: Numbers and kinds of microbial strains isolated from raw and fermented milk samples, as well as the inoculum (starter culture) used for the production of Trachanas. Identification was performed after sequencing the 16S rRNA gene fragments of bacterial DNA or the ITS region for the yeasts.

\begin{tabular}{|c|c|c|c|c|c|c|c|c|c|c|c|}
\hline \multirow{2}{*}{ Species } & \multicolumn{2}{|r|}{ Raw milk } & \multicolumn{2}{|r|}{ Starter culture } & \multicolumn{7}{|c|}{ Fermented milk } \\
\hline & $\%$ & Number of isolates & $\%$ & Number of isolates & Day 1 & Day 2 & Day 3 & Day 4 & Day 5 & $\begin{array}{c}\text { Number of } \\
\text { isolates } \\
\text { (in total) }\end{array}$ & $\%$ \\
\hline \multicolumn{12}{|l|}{ Lactic acid bacteria } \\
\hline Lactococcus lactis & 33.3 & 4 & 9.1 & 1 & 6 & 11 & 14 & 8 & - & 39 & 27.9 \\
\hline Lactococcus spp. & & $-^{*}$ & & - & - & 1 & 8 & 1 & - & 10 & 7.1 \\
\hline Lactobacillus casei/paracasei & i 8.3 & 1 & 72.7 & 8 & 4 & 3 & - & - & - & 7 & 5.0 \\
\hline Lactobacillus helveticus & & - & & - & 1 & - & - & - & - & 1 & 0.7 \\
\hline Lactobacillus gasseri & 8.3 & 1 & & - & & & & & & - & \\
\hline Lactobacillus spp. & & - & 9.1 & 1 & 2 & 1 & - & - & 25 & 28 & 20.0 \\
\hline Enterococcus faecalis & & - & & - & 1 & 1 & 2 & 3 & 1 & 8 & 5.7 \\
\hline Enterococcus faecium & & - & & - & - & - & - & - & 1 & 1 & 0.7 \\
\hline Enterococcus gallinarum & 8.3 & 1 & & - & & & & & & - & \\
\hline Enterococcus canintestini & & - & & - & - & - & - & - & 1 & 1 & 0.7 \\
\hline Enterococcus spp. & 8.3 & 1 & & - & - & 1 & 1 & 1 & - & 3 & 2.1 \\
\hline Leuconostoc mesenteroides & & - & & - & - & - & - & 1 & - & 1 & 0.7 \\
\hline Streptococcus spp. & 16.7 & 2 & & - & & & & & & - & \\
\hline \multicolumn{12}{|l|}{ Other bacteria } \\
\hline Staphylococcus epidermidis & & - & & - & 1 & - & - & - & - & 1 & 0.7 \\
\hline Macrococcus caseolyticus & 16.7 & 2 & & - & - & - & - & - & - & - & - \\
\hline Enterobacter spp. & & - & & - & - & - & - & - & 1 & 1 & 0.7 \\
\hline Acinetobacter spp. & & - & & - & - & 1 & - & - & - & 1 & 0.7 \\
\hline Acetobacter cibinongensis & & - & & - & - & - & - & - & 1 & 1 & 0.7 \\
\hline \multicolumn{12}{|l|}{ Yeasts } \\
\hline Saccharomyces unisporus & & - & 9.1 & 1 & 6 & 2 & 3 & 6 & 8 & 25 & 17.9 \\
\hline Saccharomyces spp. & & - & & - & - & - & 3 & 1 & - & 4 & 2.9 \\
\hline Kluyveromyces marxianus & & - & & - & 3 & 2 & 1 & 2 & - & 8 & 5.7 \\
\hline Total & 100.0 & 12 & 100.0 & 11 & 24 & 23 & 32 & 23 & 38 & 140 & 100.0 \\
\hline
\end{tabular}

${ }^{*}$ Empty cells represent the absence of the respective species.

More specifically, LAB species (Lactococcus, Lactobacillus, and Enterococcus) were frequently isolated from raw milk samples; Streptococcus spp. and Macrococcus caseolyticus were scarcely found, while no yeasts were isolated (Table 2). Those results are not unusual, since it is well known that $\mathrm{LAB}$, adventitious bacteria, and sometimes yeasts naturally belong to the microbiota of raw milk [13,29]. Regarding the starter culture added to raw milk, it seems that the species Lactobacillus casei/paracasei predominated over the other microorganisms.

Monitoring the fermentation process during a 5-day period, lactococci, lactobacilli, and yeasts predominated (Table 2). Lactococcus lactis and Lactococcus spp. were isolated in high frequency (35\% of the isolates), reaching higher numbers at day 3 , which is in accordance with the log counts of LAB in M17 agar, which favours the growth of Grampositive catalase negative cocci (Table 1). These bacteria are naturally occurring in raw milk [9] and they multiply when they find optimal conditions. No Lactococcus species were isolated at the end of fermentation process (day 5), most likely due to the acidic conditions created in fermented milk $(\mathrm{pH}$ 3.8 at day 5; Table 1) and the lysis of the cells [30]. On the contrary, Lactobacillus species were isolated in low numbers at the first two days, but their numbers were highly increased at the end of fermentation period (day 5). Thus, partial substitution of Lactococcus sp. microbiota by Lactobacillus spp. was undertaken after day 3 (Table 2).

As shown in Table 2, a total of 37 yeast stains were retrieved only from the fermented milk. Since no yeasts were isolated from raw milk samples (except one) and/or the starter culture, an environmental contamination is implied. Yeast spoilage is recognized as a problem primarily in fermented milk and cheeses [24]. Yeasts were isolated throughout the fermentation process with Saccharomyces unisporus predominating from the start to the end. This species was previously found to be the principal alcoholic fermentation microorganism of traditional koumiss [31]. Saccharomyces unisporus and Lactobacillus spp. seem to predominate at the 
end of milk fermentation. This is most likely the reason for high percentage in Lactobacillus species isolations of the added starter, since a part of the old batch is used to ferment the new one.

Macrococcus caseolyticus and Streptococcus spp. found in raw milk were not isolated from any sample during the fermentation process, probably due to the presence of other bacteria, such as LAB and yeasts, and the nutritional competitiveness in the milk microenvironment [32]. On the other hand, there were microorganisms (i.e., Lactobacillus helveticus and some Enterococcus species; Table 2) isolated from the fermented milk, at the different fermentation time, which were found neither in milk samples nor in the added starter culture. It is noteworthy to mention that these strains were picked from Petri dishes after cultivation; thus divergences in bacterial species detection could be due to different reasons, such as the high selectivity of some media towards specific microorganisms, which find optimal conditions for their growth [33].

\section{Conclusions}

In the present work, the composition of autochthonous microbiota of traditional Cypriot Trachanas was studied. A great biodiversity was observed in respect of the predominant species present in milk during fermentation. Results showed that Lactococcus, Lactobacillus, and yeast species contribute majorly to the completion of the fermentation. Further studies are needed to determine the technological properties of these isolates in order to reproduce this artisanal product using traditional technology.

\section{Conflicts of Interest}

None of the authors have a financial or personal relationship with other people or organisations which could inappropriately influence or bias this publication.

\section{Authors' Contributions}

Despina Bozoudi and Maria Agathokleous contributed equally to this work.

\section{Acknowledgments}

The authors gratefully acknowledge the material provided by C. Katsouras and the financial support from the Cyprus University of Technology Start-Up Fund to Dr. Dimitris Tsaltas.

\section{References}

[1] O. Daglioglu, "Tarhana as a traditional Turkish fermented cereal food. Its recipe, production and composition.," Die Nahrung, vol. 44, no. 2, pp. 85-88, 2000.

[2] A. Georgala, "The nutritional value of two fermented milk/cereal foods named 'Greek Trahanas' and 'Turkish Tarhana' : a review," Journal of Nutritional Disorders \& Therapy, vol. 3, no. 1, 2012.
[3] S. Ozdemir, D. Gocmen, and A. Y. Kumral, "A traditional Turkish fermented cereal food: Tarhana," Food Reviews International, vol. 23, no. 2, pp. 107-121, 2007.

[4] A. Y. Tamime and T. P. O'Connor, "Kishk-A dried fermented milk/cereal mixture," International Dairy Journal, vol. 5, no. 2, pp. 109-128, 1995.

[5] D. Gocmen, O. Gurbuz, R. L. Rouseff, J. M. Smoot, and A. F. Dagdelen, "Gas chromatographic-olfactometric characterization of aroma active compounds in sun-dried and vacuumdried tarhana," European Food Research and Technology, vol. 218, no. 6, pp. 573-578, 2004.

[6] S. Carpino, T. Rapisarda, G. Belvedere et al., "Effect of dehydration by sun or by oven on volatiles and aroma compounds of Trachanas," Dairy Science \& Technology, vol. 90, no. 6, pp. 715727, 2010.

[7] D. Bozoudi, M. Agathokleous, I. Anastasiou, P. Papademas, and D. Tsaltas, "Microbiological characteristics of Trachanas, a traditional fermented dairy product from Cyprus," in Proceedings of the 12th International Meeting on Mountain cheese, Padova, Italy, 2017.

[8] T. M. Cogan, M. Barbosa, E. Beuvier et al., "Characterization of the lactic acid bacteria in artisanal dairy products," Journal of Dairy Research, vol. 64, no. 3, pp. 409-421, 1997.

[9] F. Berthier, E. Beuvier, A. Dasen, and R. Grappin, "Origin and diversity of mesophilic lactobacilli in Comté cheese, as revealed by PCR with repetitive and species-specific primers," International Dairy Journal, vol. 11, no. 4-7, pp. 293-305, 2001.

[10] S. Morandi, M. Brasca, and R. Lodi, "Technological, phenotypic and genotypic characterisation of wild lactic acid bacteria involved in the production of Bitto PDO Italian cheese," Dairy Science \& Technology, vol. 91, no. 3, pp. 341-359, 2011.

[11] M. F. Scintu and G. Piredda, "Typicity and biodiversity of goat and sheep milk products," Small Ruminant Research, vol. 68, no. 1-2, pp. 221-231, 2007.

[12] M. Ortigosa, P. Torre, and J. M. Izco, "Effect of pasteurization of ewe's milk and use of a native starter culture on the volatile components and sensory characteristics of Roncal Cheese," Journal of Dairy Science, vol. 84, no. 6, pp. 1320-1330, 2001.

[13] J. T. M. Wouters, E. H. E. Ayad, J. Hugenholtz, and G. Smit, "Microbes from raw milk for fermented dairy products," International Dairy Journal, vol. 12, no. 2-3, pp. 91-109, 2002.

[14] A. Badis, D. Guetarni, B. Moussa-Boudjemâa, D. E. Henni, M. E. Tornadijo, and M. Kihal, "Identification of cultivable lactic acid bacteria isolated from Algerian raw goat's milk and evaluation of their technological properties," Food Microbiology, vol. 21, no. 3, pp. 343-349, 2004.

[15] F. Durlu-Ozkaya, V. Xanthopoulos, N. Tunail, and E. Litopoulou-Tzanetaki, "Technologically important properties of lactic acid bacteria isolates from Beyaz cheese made from raw ewes' milk," Journal of Applied Microbiology, vol. 91, no. 5, pp. 861-870, 2001.

[16] V. Xanthopoulos, D. Petridis, and N. Tzanetakis, "Characterization and classification of Streptococcus thermophilus and Lactobacillus delbrueckii subsp. bulgaricus strains isolated from traditional Greek yogurts," Journal of Food Science, vol. 66, no. 5, pp. 747-752, 2001.

[17] G. Reuter, "Elective and selective media for lactic acid bacteria," International Journal of Food Microbiology, vol. 2, no. 1-2, pp. 55-68, 1985.

[18] O. Kandler and N. Weiss, "Regular non-sporing Gram positive rods," in Bergey's Manual of Systematic Bacteriology. Sneath 
MESPHA, Holt JG Williams and Wilkins, J. G. Holt, Ed., vol. 2, pp. 1208-1234, Williams and Wilkins, Baltimore, MD, USA, 1986.

[19] J.-F. Luo, W.-T. Lin, and Y. Guo, "Method to detect only viable cells in microbial ecology," Applied Microbiology and Biotechnology, vol. 86, no. 1, pp. 377-384, 2010.

[20] M. Tristezza, L. Fantastico, C. Vetrano et al., "Molecular and technological characterization of saccharomyces cerevisiae strains isolated from natural fermentation of susumaniello grape must in Apulia, Southern Italy," International Journal of Microbiology, vol. 2014, Article ID 897428, 2014.

[21] P. Gaya, M. Babín, M. Medina, and M. Nuñez, "Diversity among lactococci isolated from ewes' raw milk and cheese," Journal of Applied Microbiology, vol. 87, no. 6, pp. 849-855, 1999.

[22] M. E. Fadda, V. Mossa, M. B. Pisano, M. Deplano, and S. Cosentino, "Occurrence and characterization of yeasts isolated from artisanal Fiore Sardo cheese," International Journal of Food Microbiology, vol. 95, no. 1, pp. 51-59, 2004.

[23] N. Desmasures, F. Bazin, and M. Guéguen, "Microbiological composition of raw milk from selected farms in the Camembert region of Normandy," Journal of Applied Microbiology, vol. 83, no. 1, pp. 53-58, 1997.

[24] G. H. Fleet, "Growth of Yeasts during Wine Fermentations," Journal of Wine Research, vol. 1, no. 3, pp. 211-223, 1990.

[25] B. C. Viljoen, "The interaction between yeasts and bacteria in dairy environments," International Journal of Food Microbiology, vol. 69, no. 1-2, pp. 37-44, 2001.

[26] I. Y. Sengun, D. S. Nielsen, M. Karapinar, and M. Jakobsen, "Identification of lactic acid bacteria isolated from Tarhana, a traditional Turkish fermented food," International Journal of Food Microbiology, vol. 135, no. 2, pp. 105-111, 2009.

[27] E. S. Lazos, G. Aggelousis, and M. Bratakos, "The fermentation of trahanas: a milk-wheat flour combination," Plant Foods for Human Nutrition, vol. 44, no. 1, pp. 45-62, 1993.

[28] O. Daglioglu, M. Arici, M. Konyali, and T. Gumus, "Effects of tarhana fermentation and drying methods on the fate of Escherichia coli 0157:H7 and Staphylococcus aureus," European Food Research and Technology, vol. 215, no. 6, pp. 515-519, 2002.

[29] L. Quigley, O. O'Sullivan, C. Stanton et al., "The complex microbiota of raw milk," FEMS Microbiology Reviews, vol. 37, no. 5, pp. 664-698, 2013.

[30] K. Papadimitriou, Á. Alegría, P. A. Bron et al., "Stress physiology of lactic acid bacteria," Microbiology and Molecular Biology Reviews, vol. 80, no. 3, pp. 837-890, 2016.

[31] G. Montanari, C. Zambonelli, L. Grazia, G. K. Kamesheva, and M. K. Shigaeva, "Saccharomyces unisporus as the principal alcoholic fermentation microorganism of traditional koumiss," Journal of Dairy Research, vol. 63, no. 2, pp. 327-331, 1996.

[32] A. S. Angelidis, "The microbiology of raw milk," in A Practical Approach, P. A. Papademas, Ed., pp. 22-69, CRC Press, 2015.

[33] P. Dolci, V. Alessandria, G. Zeppa, K. Rantsiou, and L. Cocolin, "Microbiological characterization of artisanal Raschera PDO cheese: analysis of its indigenous lactic acid bacteria," Food Microbiology, vol. 25, no. 2, pp. 392-399, 2008. 

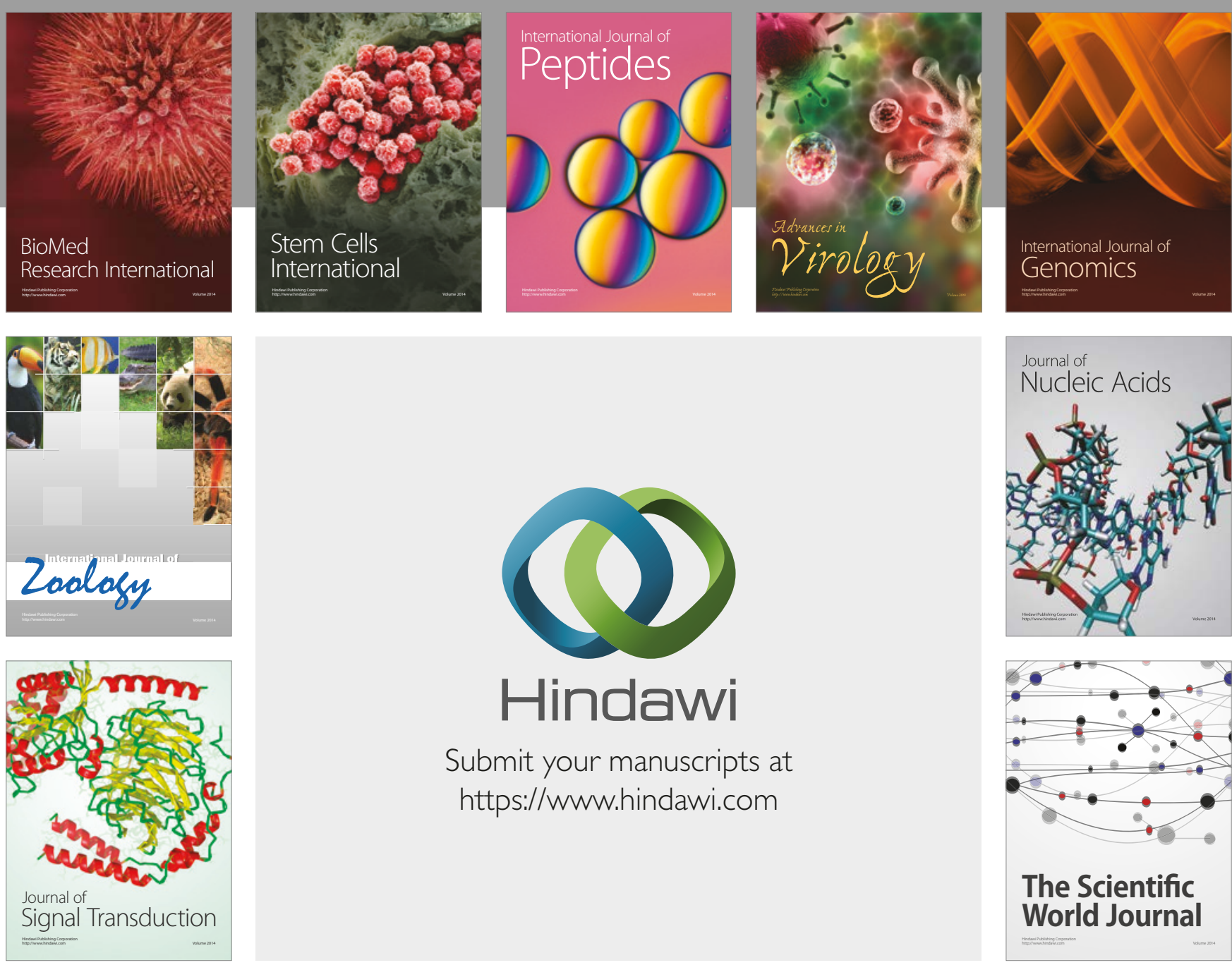

Submit your manuscripts at

https://www.hindawi.com
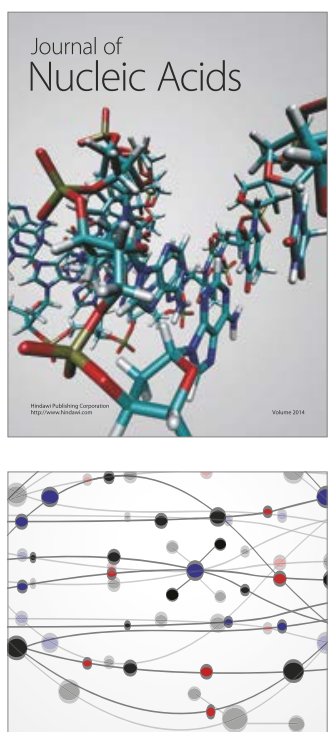

The Scientific World Journal

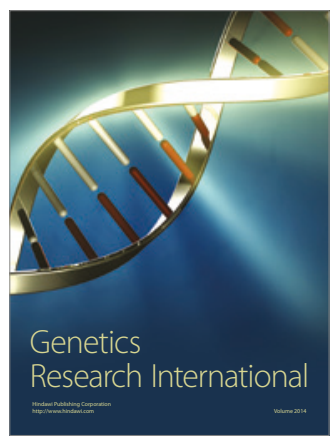

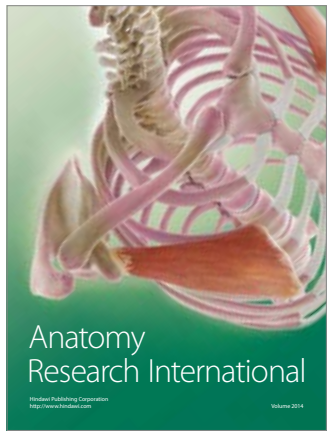

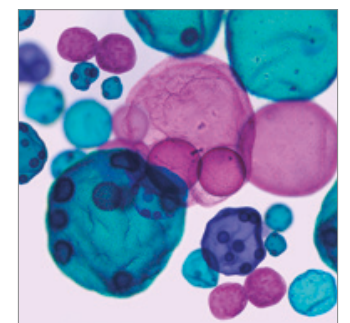

International Journal of Microbiology
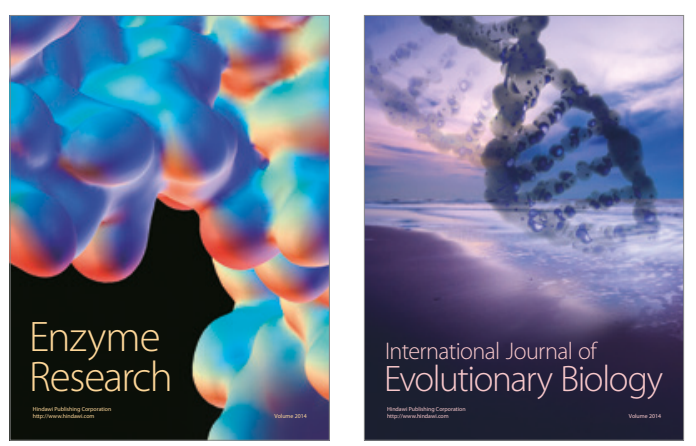
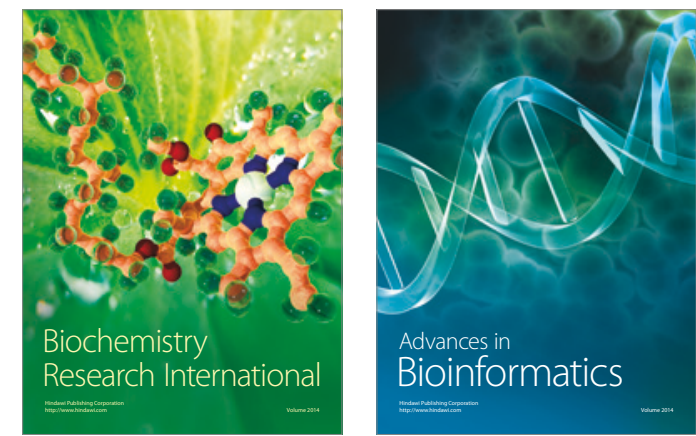

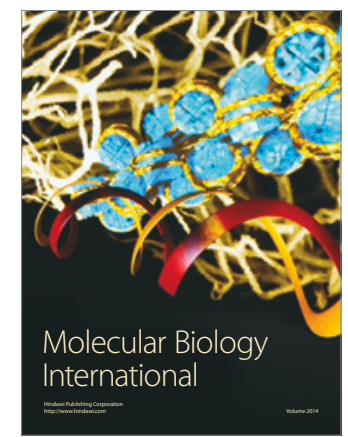

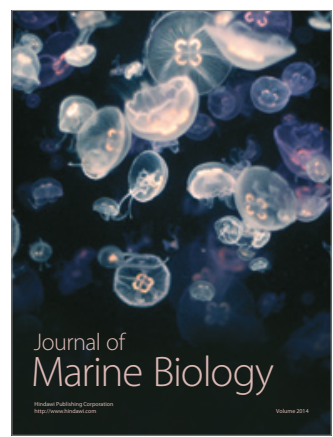

